\title{
MENTAL HEALTH IN MEDICAL STUDENTS: HOW TO COPE WITH
}

\author{
Kristina Weil (1), M. Jesús Salles (1).
}

\section{(1) Faculty of Medicine Universidad de los Andes, Department of Psychiatry, Santiago de Chile}

\author{
Keywords: medical student /mental health
}

\section{Introduction:}

Several authors report mental symptoms in health career students, especially in medicine and in medical doctors. In a systematic review and meta- analysis of 167 crosssectional studies $(n=116$ 628) and 16 longitudinal studies ( $n=5728$ ) the overall pooled crude prevalence of depression or depressive symptoms was $27.2 \%$. Suicidal ideation prevalence extracted from 24 cross-sectional studies $(n=21002)$ from 15 countries was $11.1 \%(1)$.

Other reports in undergraduate medical students prevalence rates of depression (29\%), anxiety disorders (21\%), suicidal ideation (11\%) (2) and prevalence of $50 \%$ of any mental health disorder (3). Medical student mean resilience result lower than in the general population sample (4). In our local studies students showed sleeping disorders and high rates of stress in certain career levels, using the Academic Stress Inventory.

\section{Objectives:}

-Review of publications and report of personal experience in many local studies made among our students.

-Proposal of a specific intervention to promote mental health in medical students.

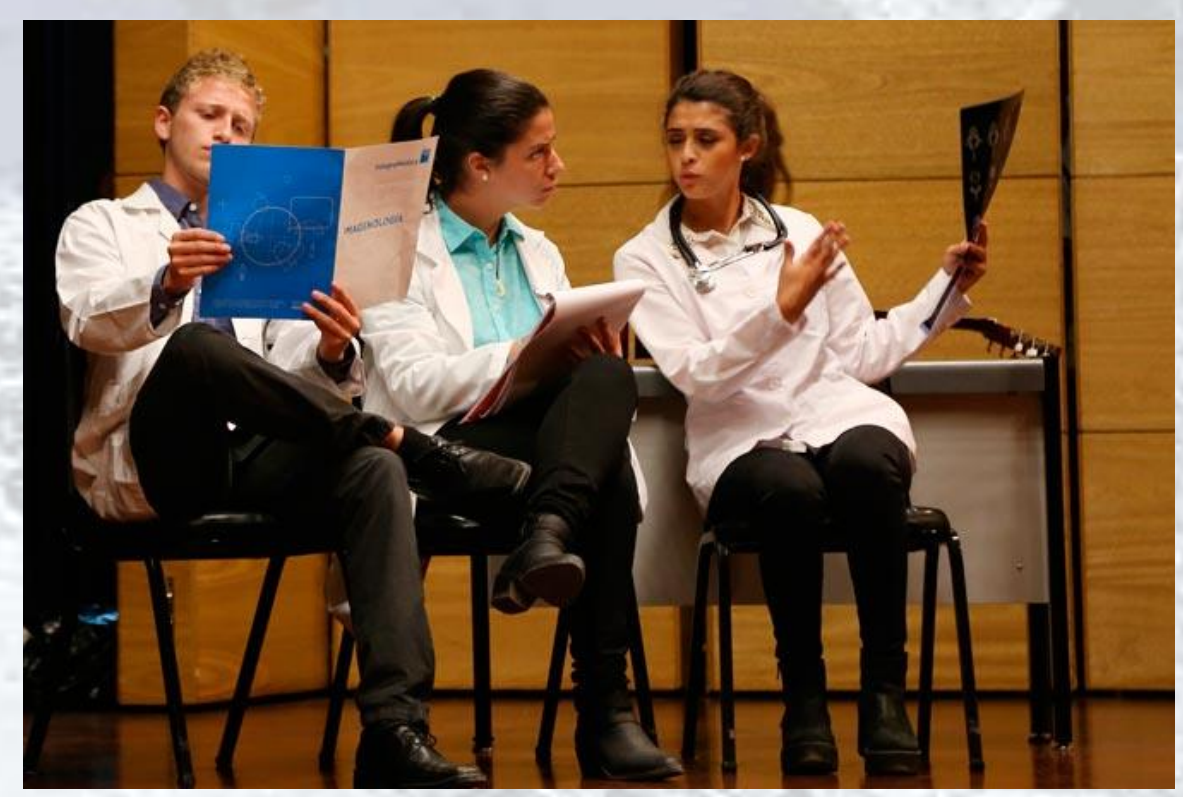

\section{Method:}

- Review of International publications and researches at our university.

- Two interactive workshops of 2 hours each about sleeping \& studying habits and about alcohol \& substance abuse were included in the first and second level of the career $(n=240)$, guided by psychiatrists. With the aim of gaining consciousness about selfbehavior, students answered individually a brief questionnaire, and discussed in groups their responses. Comments and conclusions were analyzed and shared with the class. A brief theoric presentation followed.

\section{Results:}

Symptoms of anxiety, depression, sleep disorders, abuse of alcohol and others were found in previous studies reviewed by students. They have unhealthy eating, sleeping and learning habits. Reflections on psychological aspects of studying medicine and caring for ill people were discussed. Students highly valued faculties' concern about their feelings.

\section{Conclusions:}

Medical students expect mental health support from their teaching organizations. More interventions must be developed.

1)Rotenstein L, Ramos M, Torre M, Segal B, et col. U. Harvard. Prevalence of depression, depressive symptoms and suicidal ideation among medical students: a systematic review and mata-analysis. JAMA 2016, dec 06;316821): 2214-2236. doi:10.1001/jama.2016.17324

2) Zeng, W., Chen, R., Wang, X., Zhang, Q. and Deng, W. (2019) 'Prevalence of mental health problems among medical students in China: A meta-analysis', Medicine (Baltimore), 98(18), pp. e15337.

3) Moutinho, I. L. D., Lucchetti, A. L. G., Ezequiel, O. D. S. and Lucchetti, G. (2019) 'Mental health and quality of life of Brazilian medical students: Incidence, prevalence, and associated factors within two years of follow-up', Psychiatry Res, 274, pp. 306-312.4) Houpy J, Lee W, Woodroff J, Pincvage A. Medical student resilience and stressful clinical events during clinical training. Medical Education Online, vol 22. 1320187 